\title{
Cartografia do cuidado em saúde mental no encontro entre agente comunitário de saúde e usuário
}

\author{
I 1 Jania Lurdes Pires Samudio, ${ }^{2}$ Ana Clara de Freitas Dias Costa Martins, \\ ${ }^{3}$ Letícia Carneiro Brant, ${ }^{4}$ Cristina Sampaio I
}

Resumo: O estudo mapeou parte da produção de cuidado em saúde mental que acontece no encontro entre Agente Comunitário de Saúde (ACS) e usuário na Atenção Primária à Saúde (APS). A metodologia utilizada foi a cartografia, fundamentada na esquizoanálise, teoria filosófica de Gilles Deleuze e Félix Guattari, cujo interesse é mapear as linhas de força que conectam o objeto de estudo. Para a captura da produção de cuidado, realizaram-se grupos focais com ACS de equipes de Estratégia Saúde da Família (ESF) de Montes Claros-MG. Como resultado, verificam-se deslocamentos no cuidado dos ACS, quando, saindo das linhas duras "profissionais psi cuidam" e "cuidar sem se envolver", são atravessados por linhas maleáveis e de fuga, "oferecer escuta" e "pensar sobre o encontro com o usuário"; contudo, há reterritorialização por nova linha dura: "escutar não basta". Aponta-se a potencialidade do ACS no cuidado em saúde mental na APS: um trabalhador aberto à invenção de sua subjetividade e à Reforma Psiquiátrica. Para tal, são necessários agenciamentos que contribuam para novas formas de cuidado em seu território de trabalho, dando-lhes visibilidade e reconhecimento.

> Palavras-chave: Agente Comunitário de Saúde; Saúde mental; Cartografia.

\author{
1 Universidade Estadual de \\ Montes Claros, Programa \\ de Pós-Graduação em \\ Cuidado Primário em Saúde. \\ Montes Claros-MG, Brasil \\ (jansamudio@yahoo.com.br). \\ ${ }^{2}$ Universidade Estadual de \\ Montes Claros, Curso de \\ Graduação em Medicina. \\ Montes Claros-MG, Brasil \\ (anaclarafdcosta@hotmail.com). \\ ${ }^{3}$ Universidade Estadual de \\ Montes Claros, Curso de \\ Graduação em Medicina. \\ Montes Claros- MG, Brasil \\ (letletbrant@gmail.com). \\ ${ }^{4}$ Universidade Estadual de \\ Montes Claros, Departamento \\ de Saúde Mental e Saúde \\ Coletiva, Programa de \\ Pós-Graduação em Cuidado \\ Primário em Saúde. Montes \\ Claros-MG, Brasil (sampaio. \\ cristina@uol.com.br).
}

Recebido em: 12/05/2016 Aprovado em: 25/09/2016 
O Agente Comunitário de Saúde (ACS), profissional estratégico inserido na Atenção Primária à Saúde (APS), é parte fundamental para a implantação das equipes de Estratégia Saúde da Família (ESF), bem como para o alcance de suas ações.

No Brasil, as primeiras experiências com o ACS aconteceram em 1987, no Ceará. O êxito dessa iniciativa para a população levou ao surgimento do Programa de Agentes de Saúde (PACS), que, posteriormente, se ampliou para assegurar a efetivação dos princípios do SUS (MENDES, 2012), originando, em 1991, o PACS nas regiōes Norte e Nordeste do Brasil. Priorizava-se a assistência básica à população sem acesso a condutas médicas; por isso, realizava-se desde o cadastramento da população até ações de promoção e proteção da saúde da criança e da mulher, focando os casos mais vulneráveis (GIOVANELLA; MENDONÇA, 2008).

A atuação abrangente do ACS gerou uma demanda por serviços de saúde com tecnologia de maior densidade. Por isso, juntaram-se aos ACS médicos e enfermeiros generalistas, compondo equipes responsáveis por uma população adscrita territorialmente e organizada por famílias. Constituiu-se, assim, em 1994, o Programa Saúde da Família (PSF) como política oficial da APS no Brasil (MENDES, 2012). Em 2006, pela Portaria no 648/GM de março de 2006, lançou-se a Política Nacional de Atenção Básica, estabelecendo a revisão de diretrizes e normas para a organização da Atenção Básica para o PSF e para o PACS. O PSF e sua adequada implementação são estratégicos para a consolidação do SUS, via participação social, controle social e municipalização.

O ACS passou a ter uma posição singular dentro da equipe, pois sua proximidade com a comunidade o estimula à criação de vínculos, gerando a possibilidade de intervençôes para o cuidado em saúde, tendo em vista que sua atuação objetiva ofertar qualidade de vida às pessoas (BRASIL, 2009) e constitui um elo entre a equipe e a comunidade (FORTES; SPINETTI, 2004). Tal situação exige do ACS criatividade e cumprimento não mecânico de tarefas, visto ser necessário que lide com situações de trabalho desafiadoras por estar inserido na mesma cultura e nas dificuldades das famílias acompanhadas (LAVOR, 2010).

Como a APS é a porta de entrada do sistema de saúde (STARFIELD, 2002), inclusive para os casos de transtornos mentais e usuários de crack, álcool e outras 
drogas, o ACS pode estar em contato direto com esses casos. Tal condição é preconizada pela Política Nacional de Saúde Mental, cujo cuidado deve ser ofertado por uma rede de serviços de saúde mental de base comunitária de forma eficaz e resolutiva, da qual a APS faz parte (BRASIL, 2001). Conhecida como Rede de Atenção Psicossocial (RAPS), essa rede de serviços se destina a pessoas com sofrimento ou transtorno mental e com necessidades decorrentes do uso de crack, álcool e outras drogas, no âmbito do SUS, evidenciando que a complexidade desses casos exige um número maior de dispositivos articulados entre si. A RAPS orienta-se no paradigma da Reforma Psiquiátrica de desinstitucionalização, uma vez que aposta na desconstrução do aparato psiquiátrico compreendido como instituição/prática/saberes reducionistas da complexidade do fenômeno da loucura, com vistas ao direito à cidadania dos usuários e à criação de serviços substitutivos ao hospital psiquiátrico, de base territorial (ROTELLI et al., 1990).

A APS compõe a RAPS e é constituída pelas 1) Unidades Básicas de Saúde: 1.1) Equipes de Atenção Básica; 1.2) Equipes de Atenção Básica para populações específicas: Equipe de Consultório na Rua e de apoio aos serviços do componente Atenção Residencial de Caráter Transitório; 1.3) Núcleos de Apoio à Saúde da Família (NASF) e 2) Centros de Convivência e Cultura (BRASIL, 2013).

Nas novas práticas de saúde exercidas pelas equipes de Saúde da Família, o portador de transtorno mental também passa a ser visto como alguém que necessita de cuidados integrais, que lhe proporcionem dignidade, resolutividade e inclusão social. É no seu território que esses cuidados podem acontecer, ainda mais quando se pensa na equipe de Saúde da Família, capaz de oferecer cuidados generalistas e de resolver situações que demandam intervenções imediatas; como aquelas associadas ao uso prejudicial de álcool e outras drogas, aos egressos de internaçooes psiquiátricas, ao uso inadequado de benzodiazepínicos, aos portadores de transtornos mentais graves e às situações decorrentes da violência e da exclusão social (BÜCHELE et al., 2006).

O ACS é considerado profissional da ponta do sistema de saúde, próximo das famílias e dos diversos pacientes, e, especificamente, daqueles com transtorno mental e usuários de crack, álcool e outras drogas. Capturar a produção de cuidado que acontece no encontro entre ACS e usuário permite revelar seu trabalho no sentido dos afetamentos, isso quer dizer, dos efeitos da ação de um sobre outro a partir do encontro entre ambos; efeito que pode ser potencializador ou não (ROMAGNOLI, 2003). 
Estudos sobre o cuidado do ACS em saúde constatam uma lógica instrumental e estruturada por um saber técnico e biologicista. Suas capacidades inventivas acabam por ser capturadas por essa realidade (FERREIRA et al., 2009). Isso nos levou à questão norteadora desta investigação, sobre como isso acontece no campo da saúde mental, sobretudo pelo ACS se constituir como mais um dos profissionais da Reforma Psiquiátrica.

\section{Metodologia}

Com a intenção de rastrear o cuidado em saúde mental que acontece no encontro entre ACS e usuário, ofertado no seu cotidiano de trabalho, utilizamo-nos do método cartográfico, também chamado de cartografia. Este se fundamenta na esquizoanálise, teoria filosófica proposta por Deleuze e Guattari, que concebe a realidade não de forma fixa, hierarquizada e simplificada, amparada numa verdade explicativa, conforme o modelo das ciências modernas, mas complexa, rizomática e imanente (DELEUZE, 1974; ROMAGNOLI, 2009). Pensar por imanência e rizomaticamente é considerar que a realidade está em constante transformação e é composta pelos planos das formas e das forças, que coexistem nesse processo. O plano das formas se refere ao instituído, definido, binário (homem-mulher, rico-pobre), e o plano das forças diz respeito às linhas que afetam as formas, os objetos, e os modelam. No entanto, essa configuração é sempre momentânea, pois os planos estão em constante relação de agenciamento (ESCÓSSIA; TEDESCO, 2012).

Trata-se, aqui, da noção de rizoma, que tem como imagem, a partir da botânica, o "caule [...] subterrâneo, horizontal, mais ou menos espesso, rico em reservas e com capacidade de produzir raízes e caules em cada nó; se distingue das raízes pela presença de nós, gemas e escamas" (BRASIL, 2009, p. 327). Descrição que pode ser complementada: acontece um emaranhado sem delimitação de começo ou fim, em que se podem percorrer diversas direções, entrando ou saindo de qualquer ponto, sem definir uma unidade, mas sim a multiplicidade da variedade de conexões possíveis. Essa descrição nos auxilia a acompanhar o pensamento de Deleuze e Guattari (1996), no que se refere à consideração da realidade como rizomática, compreendida pelo atravessamento das formas e das forças, como vimos acima, em uma composição complexa, horizontal e de conectividade constante. 
Nessa perspectiva, seguir um rizoma é também fazer cartografia, proposta metodológica que acompanha processos e não realidades dadas; por isso, se produzem dados e não se colhem dados, pois se investiga a processualidade e produção da subjetividade (KASTRUP, 2012). Seu objetivo é “(...) desenhar a rede de forças à qual o objeto ou fenômeno em questão se encontra conectado, dando conta de suas modulações e de seu movimento permanente" (BARROS; KASTRUP, 2012, p. 57). É isso que pretendemos conhecer, no encontro com o ACS: as forças que o atravessam no cuidado em saúde mental e que o produzem como trabalhador da Reforma Psiquiátrica. A subjetividade pode ser compreendida como formada por múltiplos componentes de subjetivação que se cruzam por conexões rizomáticas, associando-se ora a formas, ao que está estabelecido, ora a forças, ao que promove a expansão da vida, levando-se em conta as composições já feitas em determinadas circunstâncias (PARPINELLI; SOUZA, 2005).

Romagnoli (2014) esclarece ser indispensável cartografar os planos das formas e das forças que afetam o objeto de estudo, pois assim se denuncia como eles se apresentam e como se organizam, além de se conhecer quando endurecem e quando produzem vida por meio de seus rearranjos. Nesse contexto, o pesquisador se localiza na via da implicação, compreendida como “[...] dispositivo de produção de conhecimento e de transformação [...]" (ROMAGNOLI, 2014, p. 50), uma vez que pode desestabilizar as formas dominantes e lançar novas possibilidades para as diferenças. Por isso, a cartografia, como pesquisa-intervenção, transforma a realidade investigada pelo fato de o pesquisador cartógrafo ser influenciável no encontro com seu objeto: é capaz de promover novas conexôes entre as diversas forças que os constituem, por meio de suas tensóes, movimentos e deslocamentos com vistas à criação de novos agenciamentos (ROMAGNOLI, 2009; KASTRUP; BARROS, 2012).

Na busca dessa produção, participaram desta pesquisa 11 equipes de ESF, da zona urbana de Montes Claros, Minas Gerais. De cada uma dessas equipes, participou, mediante interesse e disponibilidade, um ACS com, no mínimo, um ano de exercício na função. O primeiro movimento, na busca por mapear os afetos envolvidos na atuação dos ACS, foi entrar em contato com o Secretário Adjunto de Saúde, que autorizou a realização da pesquisa. Logo após, os enfermeiros das unidades de Saúde da Família foram informados dessa autorização, bem como dos objetivos da pesquisa e participação de somente um ACS. Nesse momento, 
eles falaram da quantidade de casos de saúde mental em seus territórios e de como alguns ACS eram mais envolvidos com eles, até citando seus nomes. Algumas dessas situações se mostraram reais, quando, por exemplo, o nosso contato via telefone, disponibilizado pelo enfermeiro, com o ACS disponível e interessado em participar da pesquisa, revelou ser ele o mesmo citado pelo enfermeiro. Mas, quando não se confirmavam, ainda se mantinha a disponibilidade e interesse, constatadas nas expressões que chamaram nossa atenção: "Vai ser bom para aprender"; "Já que pode ajudar a melhorar" (referindo-se ao seu trabalho). Expressóes que parecem demonstrar possibilidades e desejo de deslocamento no cuidado em saúde mental ofertado por eles.

No contato com o ACS via telefone, novamente, esclarecemos sobre a pesquisa e a data do primeiro encontro, além de agradecermos pela disponibilidade. $\mathrm{Na}$ ocasião, os ACS confirmaram presença para a primeira de três entrevistas coletivas, quando preencheram uma ficha de identificação com dados acerca da idade, formação, tempo de serviço, equipe de origem e participação em capacitações em saúde mental. Os 11 ACS constituíram-se de oito mulheres e três homens, com faixa etária entre 23 e 64 anos, no exercício da função de um a 13 anos. Seis tinham ensino médio completo, dois cursavam ensino superior e três tinham ensino superior completo; oito deles participaram do projeto Caminhos do Cuidado - Formação em Saúde Mental (crack, álcool e outras drogas) ${ }^{1}$ e todos são integrantes de equipes de Saúde da Família localizadas em regiōes periféricas do município de Montes Claros.

Buscamos rastrear as formas e forças em jogo no cuidado em saúde mental ofertado pelos ACS no cotidiano de trabalho. Para isso, efetuamos entrevistas coletivas, a partir da concepção de grupo expressa por Barros (1994), em diálogo com Deleuze: dispositivo capaz de provocar desconstruções nos indivíduos que o compõem, com vistas à produção de novos acontecimentos e, mesmo, de "[...] descristalizações de lugares e papeis que o sujeito-indivíduo constrói e reconstrói em suas histórias" (BARROS, 1994, p. 152). Isso porque o grupo tem a potencialidade de se desterritorializar e se transformar, uma vez que a subjetividade compreendida como processo também é coletiva. Seu alcance é para além da polarização indivíduo-grupo, que remete aos opostos que se anulam; foi essa concepção de grupo que nos orientou na produção de dados desta pesquisa. 
Os encontros aconteceram à tarde, de acordo com sugestões dos ACS, em três semanas consecutivas. Cada encontro durou, aproximadamente, uma hora e meia, tendo acontecido em junho de 2015. No terceiro encontro, estiveram presentes 10 ACS, porque um deles havia se afastado temporariamente por conjuntivite. Registramos, no diário de bordo, experiências que acompanharam o desenvolvimento da pesquisa, procedimento pertinente na cartografia, porque inclui tanto pesquisadores quanto pesquisados (PASSOS; BARROS, 2012), devido aos afetamentos que surgem no encontro entre ambos.

O primeiro encontro aconteceu no dia 11 de junho de 2015, na Universidade Estadual de Montes Claros (Unimontes). Chegamos mais cedo para organizar a sala e esperar pelos ACS; assim, nos preparamos para recebê-los. Buscar estar preparados parece ter sido uma tentativa de territorializar sentimentos de insegurança e apreensão frente à desterritorialização que o método cartográfico e a filosofia de Deleuze e Guattari nos causavam, haja vista ser nossa primeira pesquisa cartográfica, o que implicava encontros para além de análises baseadas numa pretensa neutralidade. Consideramos que fomos tão afetados por essa proposta metodológica e filosófica, até então nova para nós, no sentido do bom encontro, que, tornou-se fundamental, para a realização desta pesquisa, lançarmo-nos à criação de saídas inventivas.

Os outros dois encontros aconteceram na Escola Técnica de Saúde da Unimontes, respectivamente, em 18 e 25 de junho de 2015, por se localizar em região mais acessível aos ACS. Continuamos a chegar mais cedo, como forma de organizar a sala e nos preparar para o grupo; contudo, no terceiro encontro, já nos percebíamos mais leves frente às possibilidades que surgiam.

Esses afetamentos a que fomos sujeitos refletem, também, uma formação acostumada ao regramento da experiência de pesquisa, sustentada numa política cognitiva com estabelecimentos prévios, segundo um modelo teóricometodológico com maior rigidez a ser seguida. Vivenciar a experiência da cartografia foi, e é, colocar em xeque esses antecedentes e nos depararmos com a produção de conhecimento e criação, a partir de um novo modo de estar no mundo, de habitar um território existencial - no caso, o grupo com os ACS -. É também nos colocarmos numa outra posição com o conhecimento, pois há um movimento de coengendramento entre sujeito e objeto; nesta pesquisa, entre 
os ACS e nós. E, assim, parece se esclarecer a citação - com a qual, afirmamos, concordamos vivamente: “[...] a aprendizagem da cartografia não é questão de aquisição de saber nem de transmissão de informação. É preciso praticar a cartografia" (PASSOS et al., 2012, p. 201).

O projeto da pesquisa foi aprovado pelo Comitê de Ética da Unimontes, Parecer $\mathrm{n}^{\circ} 1.042 .099 / 2015$, e os participantes assinaram o Termo de Consentimento Livre e Esclarecido. Concordaram com a gravação e filmagem das entrevistas coletivas, as quais foram, posteriormente, transcritas na íntegra.

\section{Resultados e discussão}

$\mathrm{O}$ que se produziu de conhecimento sobre o cuidado em saúde mental na APS no encontro com os ACS? O traçado do mapa dos afetos, o "entre" com os ACS, estampou, como plano das formas, um modelo de cuidado em saúde mental instituído historicamente, como a responsabilidade do especialista psiquiatra, na prescrição de medicamentos, e a do psicólogo, na escuta, em atendimentos individuais ou em grupo. Percebemos, assim, utilizando-nos do termo deleuziano, uma transcendência do pensamento ao se delimitar as ações à psiquiatria e à psicologia, uma vez que tal modo de operar hierarquiza as relações de cuidado por meio da definição de quem pode oferecer o medicamento e a escuta e quem não o pode. Nesse sentido, o modo de pensar dos ACS acaba por repetir o modelo de quem pode cuidar: o hegemonicamente estabelecido, as ciências psi. Nesse rastreio, apreendemos que o cuidado em saúde mental segue a representação de um modelo a ser seguido, sendo reproduzido o mesmo para todos, subjetividades formatadas em verdades estabelecidas, em conhecimentos reconhecidos cientificamente (FUGANTI, 1990; SCHOPKE, 2004). Isso fica claro quando os ACS explicitam sobre a importância de se ter um psiquiatra e um psicólogo na equipe para cuidar diretamente dos casos de saúde mental, pois afirmam que sua função cotidiana não é escutar sobre a história de vida do usuário:

[...] a forma da minha visita lá [...] que tem horas que desvia da função...tem horas que eu vou fazer o acompanhamento de uma situação e eles começam a contar a história da vida e [...] o qual tem hora que é a função é de um psicólogo e eles começam a falar coisas que é o próprio psicólogo que tinha que estar ali agindo [...] (GRUPO 1).

Já há outros casos que deixam de ser acompanhados devido ao fim da Residência Multiprofissional em Saúde da Família, da Unimontes, que possui consultorias em saúde mental com psiquiatra e psicólogo: 
[...] foi lá, o psiquiatra [...] aí trocou os medicamentos tal, acompanhou ela [...] levou

o psicólogo lá, tinha esse, esse momento de lazer com ela [...] essa equipe que tava lá era a equipe ehhh ...residência [...] aí saiu a residência, entrou outra [...] aí no momento não tem ninguém acompanhando, sabe? (GRUPO 1).

E, ainda, quando os grupos de acolhimento e convivência deixam de acontecer porque o psicólogo não está mais na unidade, como aparece neste trecho:

Esse grupo lá mesmo tinha, agora não tem mais, porque a psicóloga foi embora, aí não tem (GRUPO 1).

O plano das formas, nesse encontro com os ACS, parece estar constituído por linhas duras, estratificadas, nas quais, para Deleuze e Guattari (1996, p. 67), "[...] tudo parece contável e previsto, o início e o fim de um segmento, bem como a passagem de um segmento a outro". São linhas duras, que formatam e definem os modelos, a normatização e o controle, mantendo uma relação binária entre opostos e, no caso do nosso território existencial, o cuidado em saúde mental ofertado por especialistas. Isso não significa que as linhas duras sejam ruins; contudo, importa como são experimentadas nas relações. Pois o desagradável seria uma fixidez com vistas à sua reprodução, simplesmente (CASSIANO; FURLAN, 2013). Isso quer dizer que não significa que seja ruim que os ACS sejam atravessados pelas linhas duras, mas, sim, como são experimentadas essas linhas na relação com o cuidado em saúde mental: apesar de duras, se transformam ou se mantêm fixas? Modulam? Quando? Produzem vida? Como?

Seguindo a cartografia, depreendemos, segundo Deleuze e Guattari, que o rizoma:

[...] não é feito de unidades, mas de dimensões, ou, antes, de direções movediças. Ele não tem começo nem fim, mas sempre um meio pelo qual ele cresce e transborda [...] o rizoma é feito somente de linhas: linhas de segmentaridade, de estratificação, como dimensões, mas também linha de fuga ou de desterritorialização como dimensão máxima segundo a qual, em seguindo-a, a multiplicidade se metamorfoseia, mudando de natureza (DELEUZE; GUATTARI, 1996, p. 32).

Nesse sentido, por não haver um eixo que preestabeleça as relações e fluxos advindos entre os muitos que compóem o rizoma experienciado entre os ACS e nós, visto que todos e cada um somos formados por vários (DELEUZE; GUATTARI, 1996), seguimos na produção existencial desse território. A alegria como potência de agir, em sentido spinozista (SPINOZA, 2008), surge quando a vida latente é capturada na explosão de linhas de fuga e agenciamentos. Conhecer 
pela cartografia é, justamente, estar aberto ao devir a partir de singularidades do sujeito e do rompimento com constatações dadas (KIRST et al., 2003). A realidade se mostra em produção, quando, no grupo 1, a seguinte fala é introduzida:

[...] assim sobre a saúde mental voltando ao que nosso colega falou [sorriso] [...] eu até me fiz como se fosse um psicólogo, mas também eu percebi a fala dele, mas tem coisas que fala e o psicólogo que tem que ouvir só que a gente tem que ter cuidado aí, porque a nossa função como agente de saúde é também escutar. né? Às vezes têm pacientes igual a colega falou: que a própria senhora disse 'mas eu quero que alguém me escute' então assim nesse tempo todo que eu tô lá na minha equipe, a gente, nossa equipe aprendeu isso também. A gente para e dá aquela atenção para o paciente. $\mathrm{O}$ paciente quer conversar? Converse! Quer desabafar? Desabafe! [...] (GRUPO 1).

Nesse momento, há o escoamento pelo rizoma de linhas de fuga, a emergência e a sustentação de forças, que desterritorializam os estratos que comportam o especialista psicólogo como responsável pela escuta. O ACS percebe que há conteúdos que o psicólogo deve escutar, mas há outros que cabem a ele, pois faz parte da sua função estar disponível à escuta: lança-se, assim, à produção de vida. Nesse viés, Cassiano e Furlan (2013) afirmam que as linhas de fuga são ativas e imprevisíveis, podendo até ser imperceptíveis, mas, mesmo assim, promovem mudanças.

Seguindo outras direções, a linha de fuga continuou a desterritorializar outros ACS, à medida que incorporaram a possibilidade de também escutar, por terem vínculo com o usuário, como aparece no seguinte fragmento:

[...] eu sei que ela precisa de uma pessoa que converse com ela, ela se sente bem quando a gente vai lá e conversa com ela [...] às vezes, no caso que já foi falado aqui, às vezes ela tá precisando de ser ouvida, que a gente escuta o que ela quer falar com a gente (GRUPO 1).

Como apontam Deleuze e Guattari (1996), quando se dá uma ruptura pela linha de fuga, corre-se o risco de ela se organizar segundo reestratificações, novamente dando poder a uma segmentaridade. Isso aconteceu quando alguns ACS insistiram que somente escutar não basta, mas que é preciso ser dito algo, tanto por eles ou pelo psicólogo, e que este seria o melhor profissional para fazêlo. Percebe-se isso no fragmento de fala:

[...] porque não é que a gente não queira ouvir, porque a gente ouve, conforme a gente [...] ouvir ajuda. Mas às vezes não resolve só ouvir [...] (GRUPO 1).

Constatamos, então, por meio do expandir das dimensões que constituem o rizoma, que as linhas duras e flexíveis escorrem, dirigem-se a outros pontos 
não anteriormente percorridos (DELEUZE; GUATTARI, 1996). Isso faz surgir outras ligações possíveis, à medida que os ACS declararam a possibilidade de também escutar e valorizar isso em suas atividades, a partir do vínculo existente entre os usuários e eles. Deslocam-se da posição de "não é minha função escutar" para "posso escutar". Emerge, assim, a potência da vida a favor da construção de um novo território existencial, pois, nesse deslocamento, vislumbra-se a possibilidade de haver um rompimento possível com identidades cristalizadas (no caso, "quem escuta é especialista psi”) (ROMAGNOLI, 2003).

Continuamos o rastreio do movimento das forças que se agenciam no encontro entre os ACS e nós. Capturamos, nesse momento, o "entre" os ACS e os usuários. Ambos compõem corpos que se atravessam e são atravessados pelos planos das formas e forças; corpos que se atraem ou se repelem. Ao se atraírem, dizemos de um bom encontro; Romagnoli (2009) aponta que bons encontros entre corpos são capazes de promover a vida, uma vez que impulsionam para o agir, para a mudança, e maus encontros mantêm o indivíduo refém de posicionamentos endurecidos. $\mathrm{O}$ acolhimento como bom encontro se dá numa “[...] ação de aproximação, um 'estar com' e um 'estar perto de' [...] se produz na relação com algo ou alguém, na aproximação” (BRASIL, 2010, p. 06). E, nesse sentido, o acolhimento em saúde é pensado como movimentos de afecções capazes de produzir novos engendramentos que forçam problematizações da vida, alterando as formas-subjetividades para lançá-las a desvios, rupturas e invençôes. Mas, quando se repelem, podemos dizer de um mau encontro, de uma relação objetificada entre sujeito e objeto, entre ACS e usuário, em que ambos entrariam como intersubjetividades desconectadas, incapazes de promoverem agenciamentos e invenções (NEVES; HECKERT, 2010).

E o que se acolhe pelo ACS em saúde mental? O que se deixa passar pelos ACS? Rastreamos que os ACS podem não acolher casos de saúde mental quando se colocam numa posição endurecida, tomada pelo plano das formas, esperando que a solução do caso venha de outro profissional; que o usuário siga o estabelecido indo à consulta, tomando medicamento, e seguindo as orientações dos profissionais.

Conversei com a enfermeira, só que a enfermeira falou bem assim: 'eu já fui lá e vou fazer o quê?' 'eu não posso fazer nada'. Não tomou nenhuma atitude em relação à casa $[. .$.$] a gente não sabe nome de filho, não tem contato com parente dela nenhum$ pra fazer alguma coisa [...] ela disse que ia passar o caso pra psicóloga, só que até hoje 
ela não falou nada comigo e [...] a enfermeira não fez nada até agora! Aí eu mesmo, porque eu não tenho conhecimento do caso, não posso fazer nada, tô esperando a atitude da enfermeira pra ver o que eu faço (GRUPO 3).

Ou, ainda, não é diferente quando, no encontro entre ACS e usuário, o ACS reproduz a posição de orientador às famílias sobre o parente adoecido, afirmando que quem cuida é a família. Os ACS ajudam acionando os demais profissionais da equipe (médico, enfermeiro e psicólogo) ou outros serviços, para que estes tomem a decisão do que deve ser feito. Definem, assim, o cuidado a ser ofertado em saúde mental, inclusive por terem receio de se envolver com o caso, com o paciente e adoecerem também. Por isso, afirmam ser necessário haver uma separação entre os lados pessoal e profissional. Novamente, um modelo de acolhimento a ser seguido:

Eu procuro não me envolver muito, não [...] a primeira vez que vai visitar igual, eu, você acaba pouco, assim, pensando, se você envolver muito, você acaba ficando doente também...então você tem que ver com mais naturalidade [...] (GRUPO 3).

Como nosso encontro não acontece baseado na neutralidade ou na reprodução, mas justamente na via do afetamento, nesse ponto rastreamos que o trabalho humano vivo dos ACS pode ser capturado pelo trabalho morto. Isso quer dizer que seu protagonismo e autonomia podem ser envolvidos pelo aprisionamento da vida e reprodução, afetados pelas linhas duras que insistem: os demais profissionais e serviços ditam o que deve ser feito, na medida em que não querem se envolver.

Sabemos que o encontro entre ACS e usuário não acontece de forma desertificada ou regular, em que ambos não se tocam. Pelo contrário, constatamos que, justamente por ser impossível eles não se afetarem, o ACS quer se manter distante. Mas será isso possível, sendo a realidade atravessada pela multiplicidade? Parece que não, uma vez que a micropolítica do processo de trabalho se constitui do plano das formas e forças que coexistem e se atravessam. Por isso, a presença do trabalho vivo em ato pode forçar rupturas nessas posições (NEVES; HECKERT, 2010; MERHY, 2014). Assim, evidenciamos ACS desapegados dessas reproduções; criam e se dizem felizes de suas invenções, mas afirmam chegar a ser malvistos por suas equipes ou mesmo, durante a entrevista coletiva, como demasiadamente envolvidos com os casos. Isso porque escutam, buscam saber mais dos usuários com os vizinhos, familiares e profissionais, deixando 
de fazer atividades na unidade para conversar com o usuário. Pensam em como podem ajudar e, assim, encontrar saídas inventivas para os casos.

[...] eu vou buscar informaçōes sobre a esquizofrenia a partir da hora que ela me informou, eu vou procurar saber o que é, pra ver onde eu posso ajudar [...] pelo menos eu, independente de estar na minha área ou não como agente, tenho que estar pedindo à família...conversando com a família pra ver o que pode ser feito [...] é... às vezes a gente fala assim: eu não me deixo envolver, mas não tem como eu não preocupar; ele é um ser humano $[. .$.$] , acho que parte de cada um pra ver o que pode ser feito...talvez$ não envolver tanto, mas, pelo menos, preocupar com o ser humano (GRUPO 3).

E, novamente, o rizoma se rompe, dessa vez por linhas maleáveis, desterritorializando estratos sobre o acolher, cuidar sem se envolver. As linhas de segmentaridade maleável possuem "impulsos e rachaduras na imanência de um rizoma, ao invés dos grandes movimentos e dos grandes cortes determinados" (DELEUZE; GUATTARI, 1996, p. 72). Essas linhas promovem desestratificações relativas, sendo menos localizáveis, e compõem mais espaços de micropolítica, escapando mais por movimentos sorrateiros. Sendo assim, um dos ACS diz que o encontro entre eles, no espaço da pesquisa, o fez pensar como está promovendo o seu encontro com os usuários:

[...] parar um pouco e ver até que ponto a gente está sendo profissional e esse profissionalismo está sendo é suficiente para o tratamento do paciente, sabe? Às vezes, a gente precisa ser também um pouquinho mais humano [...] tem dias que estou sobrecarregada, e, por causa disso, você acaba sendo assim muito objetiva na sua visita [...] e com essas falas de [...] (refere-se a uma das ACS no grupo) a gente para e pensa [...] vamos dar uma parada e ter um olhar diferenciado com o paciente (GRUPO 3).

Rastreamos, assim, a potencialidade de um bom encontro entre os ACS e nós, à medida que desterritorializações foram possíveis para a construção de novas reterritorializaçōes no cuidado em saúde mental. E isso se fez porque as linhas que atuam na realidade estão buscando conexões, lançando-se aos afetamentos e variações contínuas de intensidade, sem se prenderem ao binarismo das relações. É isso que permite a geração de novos sentidos e novas formas de expressão: desvencilhando-se da reprodução, inventa-se a subjetividade, uma vez que ela é atravessada, rizomaticamente, por linhas duras, maleáveis e flexíveis (CASSIANO; FURLAN, 2013). Captura-se, então, a possibilidade de os ACS terem sua subjetividade produzida, e não reproduzida.

A subjetividade sempre é produzida nas relações, nunca é dada. E que o é relevante está no "entre" que se constrói no encontro entre sujeito e coletividades variadas. Por isso, pode-se dizer da multiplicidade da subjetividade, uma vez 
que ela afeta e sofre afetamentos nesses encontros. Afetamentos possíveis devido às linhas que se movimentam rizomaticamente nesse "entre". A subjetividade, portanto, não é cristalizada, mas pode ser agenciada, recriada (GUATTARI, 1992). Podemos dizer que a subjetividade dos ACS parece ter sido agenciada no encontro que se deu no grupo de entrevista, no coletivo, ao expressarem a possibilidade de inventar no encontro com os usuários, ou seja, "também escutálos", assim como "parar e pensar" sobre como estão cuidando do usuário.

Compreendemos a cartografia como pesquisa-intervenção, um método capaz de acessar processos, estados ou formas instituídas e modificá-las (PASSOS et al., 2012), a partir do encontro entre o cartógrafo e seu objeto de estudo. Isso porque o cartógrafo se lança à experiência, não estando neutro na relação com ela e nem carregado de um ponto de vista, pois se constitui de uma linha de força que desestabiliza essa realidade, aumentando o grau de abertura do instituído à liberdade de criação (PASSOS; EIRADO, 2012). Parece ter sido o que aconteceu, quando, como pesquisadores-cartógrafos, nos lançamos à possibilidade de conhecer o território existencial do cuidado em saúde mental ofertado pelo ACS e cartografamos fluxos endurecidos, mas que foram desestabilizados e se expandiram às novas conexões de cuidado em saúde mental.

\section{Considerações finais}

A proposta desta pesquisa foi conhecer e analisar os encontros dos ACS com o cuidado em saúde mental na APS, a partir do rastreio do plano das formas e forças que os afetam. Foi possível conhecer como se organizam esses planos e acessar tanto os entraves que podem endurecer o cuidado em saúde mental como as possibilidades de se produzirem novas formas de cuidado.

No processo, os ACS mostraram-se abertos à produção de suas subjetividades por meio do aprender, pois, desde o início do mapeamento dos fluxos, eles demonstraram esse interesse com a pesquisa. Contudo, as condições de trabalho das quais participam são desfavoráveis a essas invençôes subjetivas, uma vez que compõem equipes transcendentes no cuidado em saúde e saúde mental.

Quanto ao processo de subjetivação dos ACS, foi-nos possível constatar movimentos favoráveis à construção de novos modos de cuidado em saúde mental, por meio do registro de novos fluxos construídos nesse sentido no grupo, 
como o "escutar" e "pensar como têm cuidado". O encontro, no grupo, entre os

ACS, possibilitou agenciar fluxos e vislumbrar novas possibilidades de cuidado. Mas, como a realidade é rizomática, constituindo-se de invenções e, também, de estratos, constatou-se que estes nós aparecem e precisam ser cuidados para que não capturem a vida necessária à criação do cuidado em saúde mental.

Esta pesquisa apontou-nos a potencialidade do ACS no cuidado em saúde mental na APS, sendo ele um trabalhador propício à invenção de sua subjetividade e, consequentemente, da Reforma Psiquiátrica. Porém, para tal, precisa de agenciamentos que contribuam para novas formas de cuidado, os quais seriam interessantes de acontecer no seu próprio território de trabalho, para darlhe visibilidade e reconhecimento.

Por fim, como pesquisadores que acompanhamos processos, segundo a Cartografia, evidenciamos que conhecer a realidade é acompanhar seu processo de constituição, pois não se pode alcançar isso sem estarmos imersos no plano da experiência. Para conhecer sobre o cuidado em saúde mental ofertado pelos ACS, somente caminhando com eles nessa construção. E foi assim que, também, abrimo-nos às possibilidades de construção e invenção. ${ }^{2}$

\section{Referências}

BARROS, L. P. da; KASTRUP, V. Cartografar é acompanhar processos. In: PASSOS, E.; KASTRUP, V.; ESCÓSSIA, L. (Org.). Pistas do método da Cartografia: pesquisa-intervenção e produção de subjetividade. Porto Alegre: Sulina, 2012. p. 52-75.

BARROS, R. D. B. Grupo e Produção. In: LANCETTI, A. (org.). Saúde e Loucura 4. São Paulo: HUCITEC, 1994. p. 144-154.

BRASIL. Ministério da Agricultura, Pecuária e Abastecimento. Glossário ilustrado de morfologia. Brasília: Mapa/ACS, 2009.

Ministério da Saúde. Gabinete do Ministro. Portaria no 3.088, de 23 de dezembro de 2011, republicada em 21 de maio de 2013. Institui a Rede de Atenção Psicossocial para pessoas com sofrimento ou transtorno mental, incluindo aquelas com necessidades decorrentes do uso de crack, álcool e outras drogas, no âmbito do Sistema Único de Saúde (SUS). Brasília (DF): Ministério da Saúde, 2013. 

- Presidência da República - Casa Civil - Subchefia para Assuntos Jurídicos. Lei no 10.216, de 6 de abril de 2001. Política Nacional da Saúde Mental. Dispõe sobre a proteção e os direitos das pessoas portadoras de transtornos mentais e redireciona o modelo assistencial em saúde mental. Brasília (DF): Ministério da Saúde, 2001.

Secretaria de Atenção à Saúde. Núcleo Técnico da Política Nacional de Humanização. Acolhimento nas práticas de produção de saúde. 2. ed. 5. reimp. Brasília: Editora do Ministério da Saúde, 2010.

BÜCHELE, F. et al. A interface da saúde mental na atenção básica. Cogitare Enferm, Curitiba. v. 11, n. 3, p. 226-233, 2006.

CASSIANO, M.; FURLAN, R. O processo de subjetivação segundo a esquizoanálise. Psicol Soc, Belo Horizonte, v. 25, n. 2, p. 372-378, 2013.

DELEUZE, G. A lógica do sentido. São Paulo: Perspectiva, 1974.

Deleuze, G.; GUATTARI, F. Mil Platôs: capitalismo e esquizofrenia. v. 3. Rio de Janeiro: Ed 34, 1996.

ESCÓSSIA, L. da; TEDESCO, S. O coletivo de forças como plano de experiência cartográfica. In: PASSOS, E.; KASTRUP, V.; ESCÓSSIA, L. (Org.). Pistas do método da cartografia: pesquisa-intervenção e produção de subjetividade. Porto Alegre: Sulina, 2012. p. 92-108.

FERREIRA, V. S. C. et al. Processo de trabalho do agente comunitário de saúde e a reestruturação produtiva. Cad. Saúde Pública, Rio de Janeiro, v. 25, n. 4, p. 898-906, 2009. FORTES, P. A. de C.; SPINETTI, S. R. O agente comunitário de saúde e a privacidade das informações dos usuários. Cad. Saúde Pública, Rio de Janeiro, v. 20, n. 5, p. 1328-1333, 2004. FUGANTI, L. A. Saúde, desejo e pensamento. Saúde Loucura. São Paulo: Hucitec, n. 2, p. 19-82, 1990.

GIOVANELlA, L. MENDONÇA, M. H. M. Atenção Primária à Saúde. In: GIOVAnEllA, L. et al. (Org.). Políticas e Sistema de Saúde no Brasil. Rio de Janeiro: Editora FIOCRUZ, 2008. p. 575-625.

GUATTARI, F. Da produção da subjetividade. In: Caosmose: um novo paradigma estético. Rio de Janeiro: Ed. 34, 1992, p. 11-44.

KASTRUP, V. O funcionamento da atenção no trabalho do cartógrafo. In: PASSOS, E.; KASTRUP, V.; ESCÓSSIA, L. da (Org.). Pistas do método da cartografia: pesquisaintervenção e produção de subjetividade. Porto Alegre: Sulina, 2012. p. 32-51.

KASTRUP, V.; BARROS, L. P. da. Movimentos-funções do dispositivo na prática da cartografia. In: PASSOS, E.; KASTRUP, V.; ESCÓSSIA, L. (Org.). Pistas do método da cartografia: pesquisaintervenção e produção de subjetividade. Porto Alegre: Sulina, 2012. p. 76-91.

KIRST, P. G. et al. Conhecimento e cartografia: tempestade de possíveis. In: FONSECA, T. M. G.; KIRST, P. G. (Org.). Cartografias e devires: a construção do presente. Porto Alegre: UFRGS, 2003. p. 91-101. 
LAVOR, A. C. H. O agente comunitário: um novo profissional da saúde. In: BRASIL.

Ministério da Saúde. Secretaria de Atenção à Saúde. Departamento de Atenção Básica. Memórias da saúde da família no Brasil. Brasília: Ministério da Saúde, 2010. p. 16-19.

MENDES, E. V. O cuidado das condiçôes crônicas na atenção primária à saúde: o imperativo da consolidação da Estratégia da Saúde da Família. Brasília: Organização Pan-Americana da Saúde, 2012.

MERHY, E. E. Saúde: a cartografia do trabalho vivo. 4. ed. São Paulo: Hucitec, 2014.

NEVES, C. A. B.; HECKERT, A. L. C. Micropolítica do processo de acolhimento em saúde. Estud. Pesq. Psicol., Rio de Janeiro, v. 10, n. 1, p. 151-168, 2010.

PARPINELLI, R. S.; SOUZA, E. W. F. de. Pensando os fenômenos psicológicos: um ensaio esquizoanalítico. Psicol. Estud., Maringá, v. 10, n. 3, p. 479-487, dez. 2005.

PASSOS, E.; BARROS, R. B. A cartografia como método de pesquisa-intervenção. In: PASSOS, E.; KASTRUP, V.; ESCÓSSIA, L da (Org.). Pistas do método da cartografia: pesquisa-intervenção e produção de subjetividade. Porto Alegre: Sulina, 2012. p. 17-31.

PASSOS, E.; EIRADO, A do. Cartografia como dissolução do ponto de vista do observador. In: PASSOS, E.; KASTRUP, V.; ESCÓSSIA, L da (Org.). Pistas do método da cartografia: pesquisa-intervenção e produção de subjetividade. Porto Alegre: Sulina, 2012. p. 109-130.

PASSOS, E.; KASTRUP, V.; ESCÓSSIA, L da. Posfácio - sobre a formação do cartógrafo e o problema das políticas cognitivas. In: Pistas do método da cartografia: pesquisaintervenção e produção de subjetividade. Porto Alegre: Sulina, 2012. p. 201-205.

ROMAGNOLI, R. C. A cartografia e a relação pesquisa e vida. Psicol. Soc., Florianópolis, v. 21, n. 2, p. 166-173, 2009.

. O conceito de implicação e a pesquisa-intervenção institucionalista. Psicol. Soc., Belo Horizonte, v. 26, n. 1, p. 44-52, 2014.

. Os encontros e a relação familiar: uma leitura deleuziana. Arq. Bras. Psicol., Rio de Janeiro, v. 55, n. 1, p. 21-30,2003.

ROTELLI, F.; LEONARDIS, O.; MAURI, D. Desinstitucionalização, uma outra via. Trad. Fernanda Nicácio. In: NICÁCIO, F. (Org.). Desinstitucionalização. São Paulo: Hucitec, 1990. p. 17-59.

SCHOPKE, R. O pensamento como ultrapassamento da razão clássica. In: SCHOPKE, R. Por uma filosofia da diferença: Gilles Deleuze, o pensador nômade. Rio de Janeiro: Contraponto; EDUSP: São Paulo, 2004. p. 19-42.

SPINOZA, B. de. Ética. Belo Horizonte: Autêntica, 2008.

STARFIELD, B. Atenção Primária: Equilíbrio entre Necessidades de Saúde, Serviços e Tecnologia. Brasília: UNESCO-Ministério da Saúde, 2002. 


\section{Notas}

${ }^{1}$ O Ministério da Saúde, em parceria com a Fundação Oswaldo Cruz, o Grupo Hospitalar Conceição e a Rede de Escolas Técnicas do SUS (RET-SUS) ofereceu, entre 2013 a 2014, o curso de Formação em Saúde Mental, com ênfase em crack, álcool e outras drogas, para ACS e Auxiliares e Técnicos de Enfermagem em todo o território nacional. Disponível em: <http://www.caminhosdocuidado.org/ sobre-o-projeto/>

2 J.L.P. Samudio participou de todas as etapas da elaboração do artigo: concepção do estudo, planejamento, coleta de dados, análise e interpretação dos dados e redação do artigo. A.C.F.D.C. Martins e L.C. Brant participaram do planejamento do estudo, coleta e análise de dados e redação do artigo. C.A. Sampaio orientou todas as etapas da pesquisa, participou da concepção do estudo, planejamento, coleta e interpretação de dados, redação e revisão crítica do artigo. 


\section{Map-making in mental health care in meeting of health community agent and users}

The study mapped part of the production of mental health care that happens in the meeting between Community Health Agent (ACS) and users in Primary Health Care (PHC). The methodology used was cartography, based on schizoanalysis, the philosophical theory of Gilles Deleuze and Felix Guattari, whose interest is to map the lines of force that connect the object of study. To capture care production, focus groups were conducted with ACS from the Family Health Strategy (ESF) teams of Montes Claros-MG, Brazil. As a result, there is dislocation in the care of ACS, when, leaving the hard lines "psi professionals care" and "care without getting involved," are crossed by malleable lines and escape, "offer listening" and "thinking about the encounter with users". However, there is reterritorialization through a new hard line: "listening is not enough". The potential of ACS in mental health care in APS is pointed out: a worker open to the invention of his subjectivity and to the Psychiatric Reform. In order to do this, it is necessary to organize agencies that contribute to new forms of care in their territory, giving them visibility and recognition.

Keywords: community health agents; mental health; cartography. 